\title{
CORRECTION
}

\section{Correction to: More tendon degeneration in patients with shoulder osteoarthritis}

\author{
Mustafa Ibrahim ${ }^{1,2} \cdot$ Jüri-Toomas Kartus ${ }^{1,2} \cdot$ Sonja Eriksson Steigen ${ }^{3,4} \cdot$ Randi Olsen $^{5} \cdot$ Khaled Meknas $^{6,7}$
}

Published online: 2 November 2018

๑) European Society of Sports Traumatology, Knee Surgery, Arthroscopy (ESSKA) 2018

\section{Correction to: \\ Knee Surgery, Sports Traumatology, Arthroscopy https://doi.org/10.1007/s00167-018-5186-x}

Unfortunately, the given name and the family name of the authors were incorrectly identified in the original article. The author names are corrected here by this correction paper. The original article has been corrected.

The original article can be found online at https://doi.org/10.1007/ s00167-018-5186-x.

Khaled Meknas

khaled.meknas@uit.no; khaled.meknas@unn.no

1 Department of Orthopedics, NU-Hospital Group,

Trollhättan/uddevalla, Sweden

2 University of Gothenburg Sweden, Gothenburg, Sweden

3 Diagnostic Clinic, Clinical Pathology, University Hospital of Northern Norway, Troms $\varnothing$, Norway

4 Institute of Medical Biology, Faculty of Health Sciences, University of Troms $\varnothing$, Troms $\varnothing$, Norway

5 Department of Electron Microscopy, Institute of Medical Biology, University of Troms $\varnothing$, Troms $\varnothing$, Norway

6 Department of Orthopedics, University Hospital North Norway, 9038 Troms $\varnothing$, Norway

7 Orthopedics Research Group, Institute of Clinical Medicine, The Arctic University of Norway, 9037 Troms $\varnothing$, Norway 